\title{
DRAG ANALYSIS OF AERODYNAMIC BRAKING SYSTEM FOR THE HYPERLOOP POD
}

\author{
Syed Habeeb ${ }^{1,}, K_{a v a t i}$ Aakaanksha ${ }^{2, A b d u l ~ R a h m a n}{ }^{3,}$ Ms. D Anitha ${ }^{4}$, \\ Dr. D Govardhan ${ }^{5}$ \\ ${ }^{I}$ Pg Scholar, Department Of Aerospace Engineering, Institute Of Aeronautical Engineering, Dundigal, \\ Hyderabad, Telangana, India 500043.
}

${ }^{2}$ Pg Scholar, Department Of Aerospace Engineering, Institute Of Aeronautical Engineering, Dundigal, Hyderabad, Telangana, India 500043.

${ }^{3} \mathrm{Pg}$ Scholar, Department Of Aerospace Engineering, Malla Reddy College Of Engineering And Technology, Kompally, Hyderabad, India 500100.

${ }^{4}$ Assistant Professor, Department Of Aerospace Engineering, Institute Of Aeronautical Engineering, Dundigal, Hyderabad, Telangana, India 500043.

${ }^{5}$ Professor \& Head, Department Of Aerospace Engineering, Institute Of Aeronautical Engineering, Dundigal, Hyderabad, Telangana, India 500043.

Article DOI: https://doi.org/10.36713/epra8401 DOI No: 10.36713/epra8401

\begin{abstract}
This research presents the results of the aerodynamic brake plates mounted on the hyperloop pod, on a fluid flow field, and overall braking force under the same velocity with different angle deployment of the brake plates. Aerodynamic brake plates are designed to generate the braking force by increasing the aerodynamic drag when It was deployed against the fluid flow, in this research three plates are used one is a horizontal plate mounted on the roof of the pod and the remaining two are vertical plates which are mounted on the left and right side of the hyperloop pod. In this research to develop the case studies different combinations of angle deployment of the brake plates are used, the sixteen cases of hyperloop pods with different angle deployment of brake plates are designed by using CATIA V5-6R. the flow simulation was made by Ansys CFX software for sixteen cases of the pods with different angle deployment of the brake plates under the same velocity.

This research founds that the aerodynamic drag force is a function of angle deployment of the brake plates under the same velocity, drag force can increase or decrease by changing the angles of the brake plates. the result shows that 2.4 times of drag force increased for a fully deployed angle of attack of the brake plates when compared with the the same pod with no brake plates shows us that employing the brake plate increases the drag force This outcome will provide a major contribution to the development of the aerodynamic braking system of the hyperloop pod.
\end{abstract}

KEYWORDS: hyperloop pod, aerodynamic drag, $k-\omega$ model, aerodynamic brake 


\section{SJIF Impact Factor 2021: 8.013| ISI I.F.Value:1.241| Journal DOI: 10.36713/epra2016 ISSN: 2455-7838(Online) EPRA International Journal of Research and Development (IJRD)}

\section{INTRODUCTION}

Hyperloop is a hypothetical transportation system that is designed to decrease cost and relative time travel from any place. It is a proposed high-speed mass transportation system for both passenger and cargo. Hyperloop is also defined as a sealed tube or system of tubes in which a pod travels without any air resistance or friction, Passengers being transported through the tube is not a new notion. George Medhurst, a British mechanical engineer, and inventor received the first patent for transporting products in tubes in 1799 . Medhurst published a pamphlet in 1812 outlining his plan to carry persons and cargo through air-tight tubes propelled by air. Other comparable systems were suggested or experimented with within the early 1800 s. In July 2012, during a PandoDaily event in Santa Monica, California, Elon Musk first announced his plans for a "fifth mode of transportation," dubbed the Hyperloop. This proposed high-speed mode of transportation would have the following features: weather resistance, collision-free operation, double the speed of an aircraft, minimal power usage, and energy storage for 24-hour operation. From late 2012 through August 2013, a team of engineers from Tesla and SpaceX collaborated on Hyperloop conceptual modeling. This describes one potential design, function, pathway, and cost of a hyperloop system. The MIT Hyperloop team created the first Hyperloop pod prototype. Electrodynamic suspension and eddy current braking are used in their design. In November 2020, Virgin Hyperloop completed the first-ever passenger test of Hyperloop technology with two company workers.

The contact between the pod and the ground is nullified by using Electro Dynamic Suspension [1], so there will be no contact friction, and propulsion in the hyperloop pod is generated by using Linear Induction Motors, which is used to accelerate or deaccelerate the pod [2]. The hyperloop concept was proposed to operate at 0.015 psi 100 pa which is about $1 / 1000$ of the earth's atmospheric pressure [2].

The effect of drag reduction is negligible when the vacuum pressure is less than $1000 \mathrm{~Pa}$. As the vacuum pressure increases from 1000 to $10000 \mathrm{~Pa}$, the drag reduction effect enhances slowly and then increases rapidly beyond $10000 \mathrm{~Pa}$ [3]. It was identified that below the pressure of $10,000 \mathrm{~Pa}$ the drag reduction is not significant, so the tube pressure should be maintained nearly or above 10,000pa this allows for further scope of improvement in the aerodynamic performance. The changes in the pod, brake plates design result in the variation of aerodynamic forces. Currently, braking systems available for the hyperloop pod are friction brakes and eddy current brakes, these two brake systems require a lot of maintenance and parts replacement. An alternative to this braking system is an aerodynamic braking system which depends on the aerodynamic forces. The aerodynamic braking system uses the drag force to decelerate the hyperloop pod, advantages of the drag-based aerodynamic braking system are less power consumption, more effectiveness in high velocity, easy control, easy installation, and less maintenance required. The purpose of the paper is to identify the effectiveness of the drag-based aerodynamic braking system using three braking plates with different angles under the same velocity.

\section{METHODOLOGY}

Inside the tube, the flow is in low pressure, while dealing with the low-pressure flow we have to verify whether the continuum approach is applicable to solve the flow field at the given operating condition. Knudsen number( $\mathrm{kn})$ is a dimensionless number, it is defined as the ratio of the molecular mean free path length to the characteristic length of the model if $\mathrm{kn}<0.01$ then the flow is a continuum. After evaluating the Knudsen number $(\mathrm{Kn})$ we got the result $6.307 \mathrm{x}$ $10^{-7}$. From this, we can say that the continuum approach is applicable to solve the flow field around the pod.

Knudsen number Formula give as

$$
K_{n}=\frac{K_{B} T}{\sqrt{2} \pi d^{2} p L}
$$

In this study k- $\omega$ SST Turbulence model is used. k- $\omega$ turbulence model is a two-equation model that predicts by evaluating partial differential equations (PDE) for the turbulence kinetic energy $k$ and the specific turbulence dissipation rate $\omega$, the $k-\omega$ model handles separated flows well, where large adverse pressure gradients exist. The SST model predicts accurately the flow separation and flow transition from laminar to turbulent. 


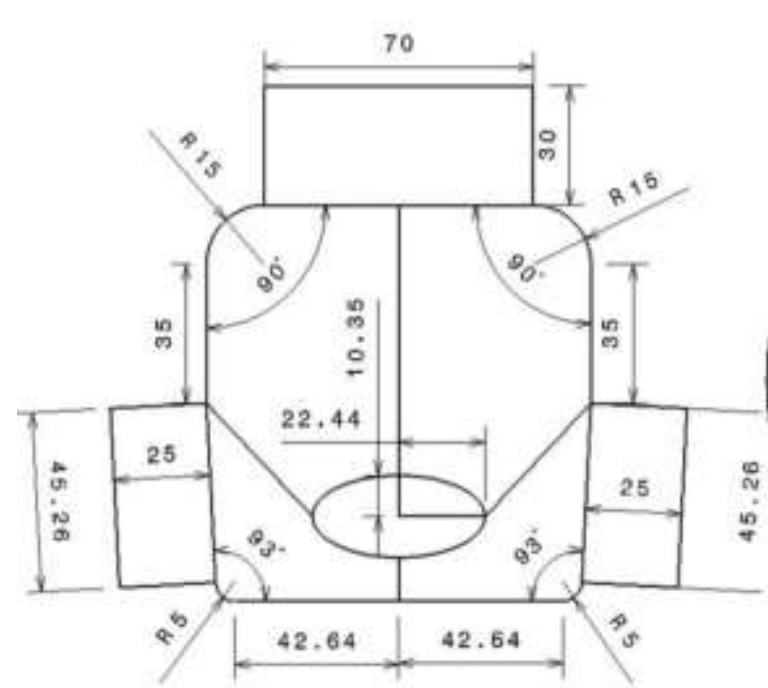

Zoom View Of The Pod

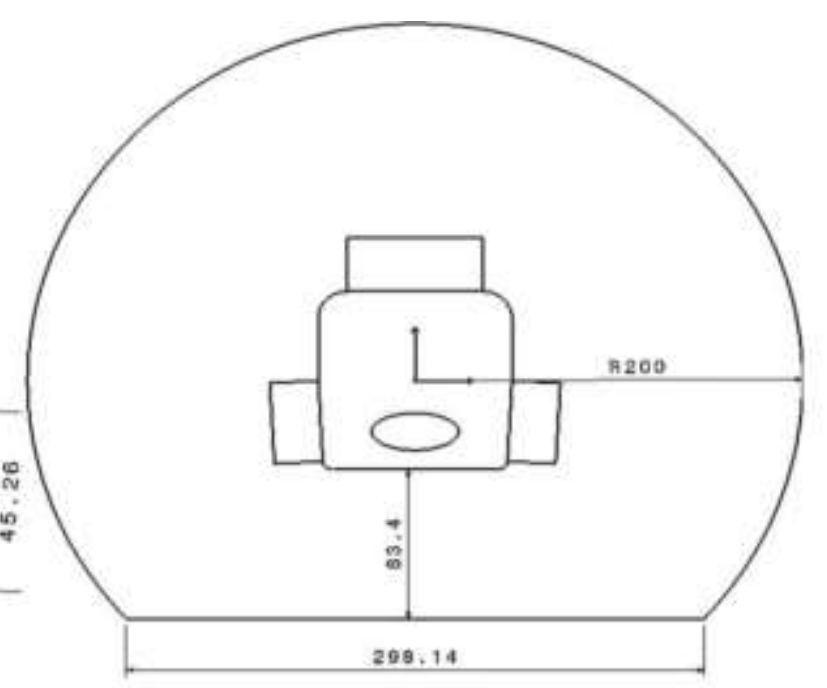

Front View

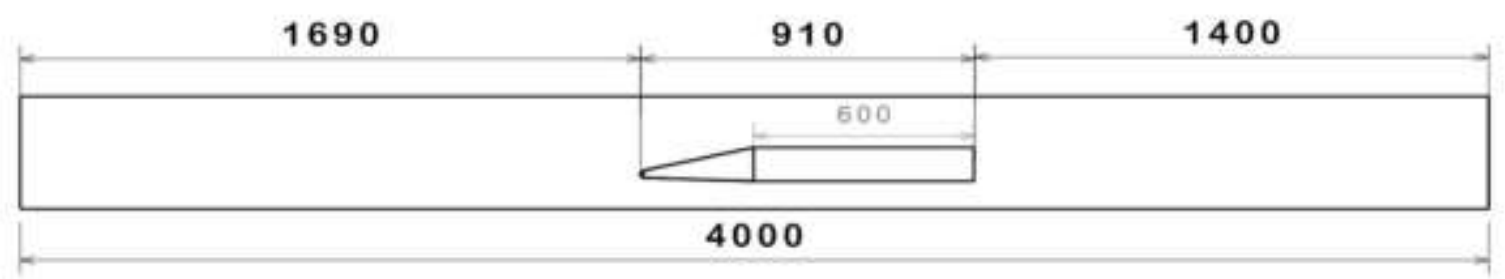

\section{Side view}

Figure 1: Hyperloop Pod Model, and Tube

Hyperloop Pod, brake plates, and tube were created using CATIA V5-6R, a constructional sketch of a pod, brake plates, and a tube is shown in figure 1. three brake plates were mounted on the pod, horizontal brake plate with an area of $0.002 \mathrm{~m}^{2}$ on the roof of the pod, vertical brake plates with an area of $0.001 \mathrm{~m}^{2}$ one on the left side and another on the right side of the pod as shown in figure 1. From CATIA V5-6R the model was imported in Ansys CFX, the mesh was generated on the model. After completing the mesh generation, boundary conditions are given as shown in figure 2 . The turbulence model was selected after that numerical solution was made by the solver.

Numerical analysis was done to find the effect of aerodynamic brake on the pod with a velocity of $126.944 \mathrm{~m} / \mathrm{s}$ by using different angles of the brake plates, angle deployment of the brake plates are represented in table 1 .

\begin{tabular}{|c|c|c|c|}
\hline Case & Horizontal top plate angle & Vertical left plate angle & Vertical right plate angle \\
\hline 1 & $90^{0}$ & $90^{0}$ & $90^{0}$ \\
\hline 2 & $90^{0}$ & $45^{0}$ & $45^{0}$ \\
\hline 3 & $90^{0}$ & $30^{0}$ & $30^{0}$ \\
\hline 4 & $90^{0}$ & $0^{0}$ & $90^{0}$ \\
\hline 5 & $45^{0}$ & $90^{0}$ & $45^{0}$ \\
\hline 6 & $45^{0}$ & $45^{0}$ & $30^{0}$ \\
\hline 7 & $45^{0}$ & $30^{0}$ & $0^{0}$ \\
\hline 8 & $45^{0}$ & $0^{0}$ & $90^{0}$ \\
\hline 9 & $30^{0}$ & $90^{0}$ & $45^{0}$ \\
\hline 10 & $30^{0}$ & $45^{0}$ & \\
\hline
\end{tabular}

(6) 2021 EPRA IJRD | Journal DOI: https://doi.org/10.36713/epra2016 | www.eprajournals.com |80 | 
SJIF Impact Factor 2021: 8.013| ISI I.F.Value:1.241| Journal DOI: 10.36713/epra2016

ISSN: 2455-7838(Online)

EPRA International Journal of Research and Development (IJRD)

Volume: 6 | Issue: 9 | September 2021

- Peer Reviewed Journal

\begin{tabular}{|c|c|c|c|}
\hline 11 & $30^{0}$ & $30^{0}$ & $30^{0}$ \\
\hline 12 & $30^{0}$ & $0^{0}$ & $0^{0}$ \\
\hline 13 & $0^{0}$ & $90^{0}$ & $45^{0}$ \\
\hline 14 & $0^{0}$ & $45^{0}$ & $30^{0}$ \\
\hline 15 & $0^{0}$ & $30^{0}$ & $0^{0}$ \\
\hline 16 & $0^{0}$ & $0^{0}$ & \multicolumn{2}{c|}{} \\
\hline
\end{tabular}

Table.1: Angle deployment arrangement of the plates

Boundary conditions are velocity inlet where a static pressure $(11 \mathrm{kpa})$, static temperature (always $300 \mathrm{~K}$ ), and velocity $(126.944 \mathrm{~m} / \mathrm{s})$ are imposed. The surface of the pod is considered as a no-slip adiabatic wall, the tube is assumed as a free slip adiabatic wall and the pressure outlet is assumed as a static pressure $(10 \mathrm{kpa})$, $\mathrm{k}-\omega$ SST Turbulence model considered.

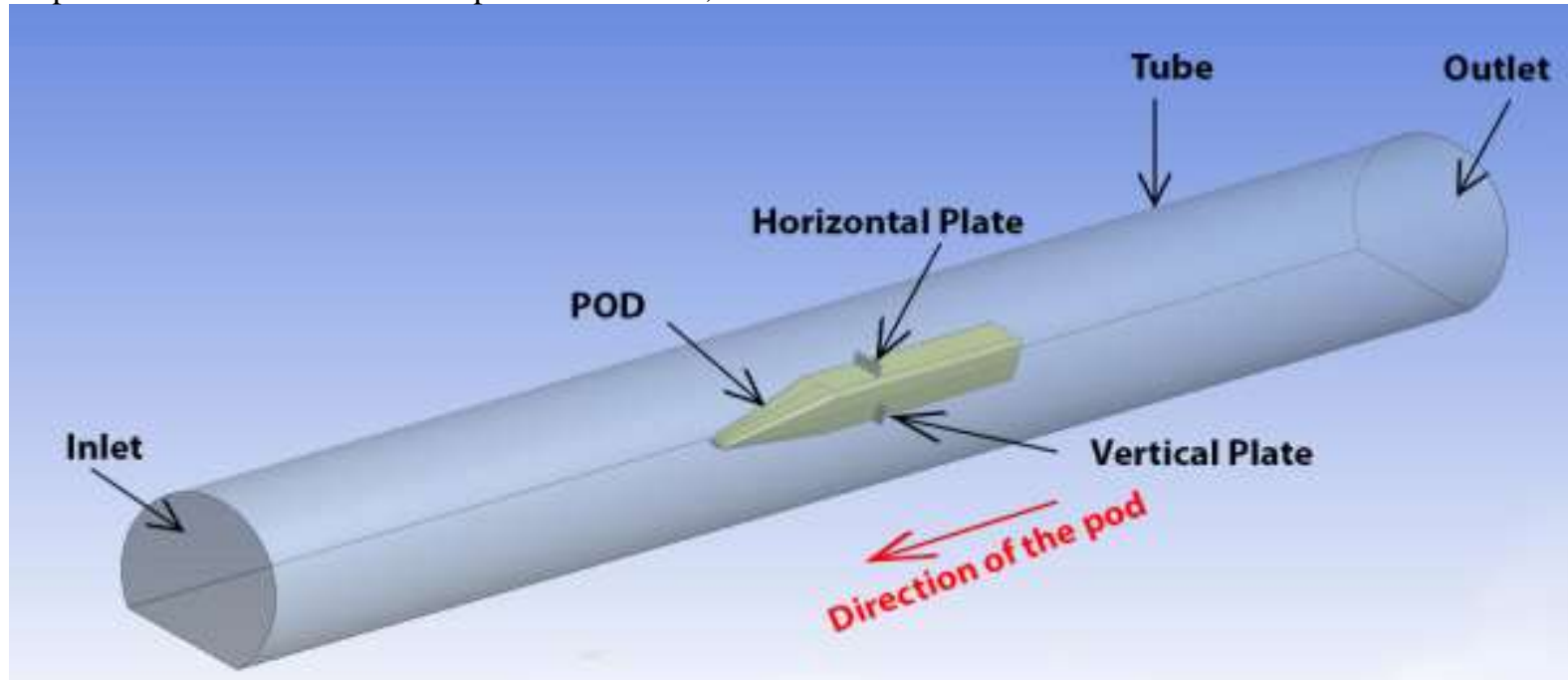

Figure .2: Representing a 3D model of pod with brake plates traveling in tube and boundary condition

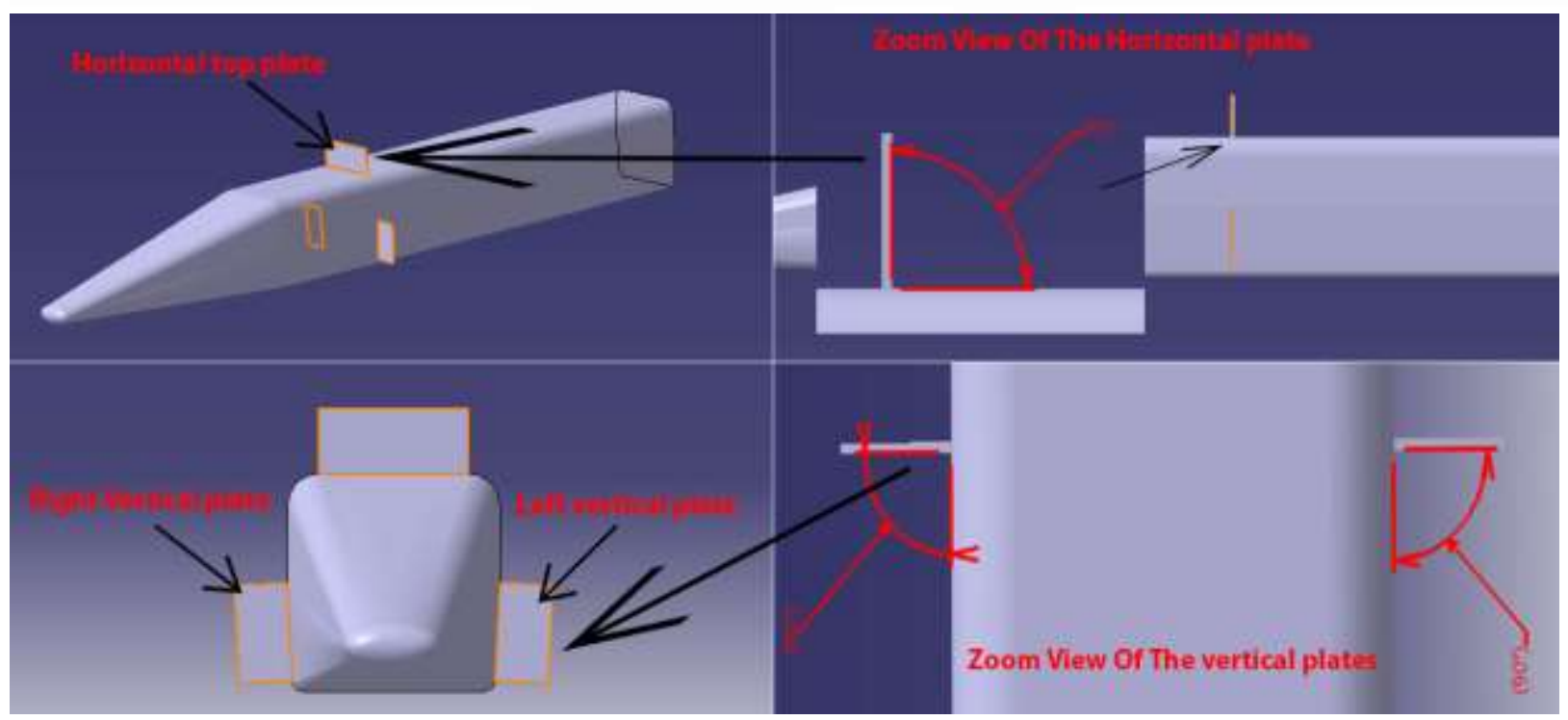

Figure.3: Aerodynamic brake plates position on the pod with angles movement

2021 EPRA IJRD | Journal DOI: https://doi.org/10.36713/epra2016 | www.eprajournals.com |81 | 


\section{SJIF Impact Factor 2021: 8.013| ISI I.F.Value:1.241| Journal DOI: 10.36713/epra2016 ISSN: 2455-7838(Online) EPRA International Journal of Research and Development (IJRD)}

To develop the case studies different combinations of angle deployment of the brake plates are created. Total combinations are made for simulation are sixteen as represented in table1. For simulation working fluid is considered as an ideal gas with the k- $\omega$ SST Turbulence model. The sixteen cases of simulation using Ansys CFX have been developed namely(velocity, pressure, force) profiles. Velocity profile gives the variation in a field flow velocity along with the pod, pressure profile gives the variation in the field flow pressure along with the pod, force result gives the amount of drag and lift generated by the fluid flows on the pod surface.

\section{RESULTS AND DISCUSSIONS}

After completing the simulation of the sixteen cases, we have noticed that there is a change in flow properties, due to the straight hitting fluid on the pod front portion and brake plates. When aerodynamic brake plates are applied against the flow, head-tip and brake plates of the pod were identified with maximum pressure along with stagnation point. At a higher angle of attack of the brake plates, the pressure build-up in the front portion of the pod is higher. The front portion of the pod, brake plates has higher pressure, and behind the plates, there was a drop in the pressure due to the flow separation which is shown in figure4. The pressure difference between the front and behind the brake plates generates the drag force, which is helpful to decelerate the pod. The force results of sixteen cases are shown in table 2. From this table we have observed due to the variation of the angle of attack of the brake plates drag and negative lift force generated, the higher drag force is seen in case 1 due to the higher angle of attack of the brake plates, and lower drag force is seen in the case 16 due to the lower angle of attack of the brake plates. The highest negative lift was found in case 5 and the lowest negative lift was found in case 16.
Because of the fluid flow blockage on the roof of the pod due to the horizontal brake plate, the fluid flow at the bottom seemed to accelerate as shown in figure 5 . As the flow velocity increases at the bottom then the pressure decreases which generates a negative lift force on the pod, this negative lift force can be utilized to stabilize the pod. The downward force generated by the pod with different angle of attack of the brake plates is represented in table 2. From table 2 we have observed that due to the variation of the angle of attack of the brake plates drag and negative lift force generated, the higher drag force is seen in case 1 due to the higher angle of attack of the brake plates, and lower drag force seen in the case 16 due to the lower angle of attack of the brake plates. The highest negative lift was found in case 5 and the lowest negative lift was found in case 16. It was noticed that an increase in the angle of attack increases the drag force. After observing all cases, we can say that fully deployed brake plates in case 1 give more drag when compared to the remaining cases. Deceleration of the pod fully depends on the angle of attack of the brake plates, if high brake force is required then the angle of attack of the brake plates should be fully deployed, if less brake force is required then the angle of attack of the brake plate should be less. It was identified that 2.4 times of drag force was increased on the pod when compared between the pod with a fully deployed angle of attack plates and the pod with a zero angle of attack plates. Eddy current brake system braking force decreases after at a certain value of the speed rises, the braking force decreases when the speed increases. The drag base braking system is more effective in decelerating the pod compared to the eddy current braking system. The braking force of the dragbased braking system increases as the velocity increases because drag force is proportional to the square velocity. 


\section{EPRA International Journal of Research and Development (IJRD)}

\begin{tabular}{|l|c|c|c|l|l|}
\hline Case & $\begin{array}{c}\text { Horizontal top plate } \\
\text { angle }\end{array}$ & $\begin{array}{c}\text { Vertical left } \\
\text { plate angle }\end{array}$ & $\begin{array}{c}\text { Vertical right } \\
\text { plate angle }\end{array}$ & \multicolumn{1}{|c|}{ Drag (n) } & Lift (n) \\
\hline 1 & $90^{0}$ & $90^{0}$ & $90^{0}$ & 131.887 & -13.441 \\
\hline 2 & $90^{0}$ & $45^{0}$ & $45^{0}$ & 115.291 & -9.231 \\
\hline 3 & $90^{0}$ & $30^{0}$ & $30^{0}$ & 106.185 & -8.057 \\
\hline 4 & $90^{0}$ & $0^{0}$ & $0^{0}$ & 90.503 & -4.337 \\
\hline 5 & $45^{0}$ & $90^{0}$ & $90^{0}$ & 115.979 & -14.329 \\
\hline 6 & $45^{0}$ & $45^{0}$ & $45^{0}$ & 99.732 & -10.300 \\
\hline 7 & $45^{0}$ & $30^{0}$ & $30^{0}$ & 90.506 & -8.741 \\
\hline 8 & $45^{0}$ & $0^{0}$ & $0^{0}$ & 75.914 & -6.502 \\
\hline 9 & $30^{0}$ & $90^{0}$ & $90^{0}$ & 107.598 & -12.880 \\
\hline 10 & $30^{0}$ & $45^{0}$ & $45^{0}$ & 91.2294 & -9.613 \\
\hline 11 & $30^{0}$ & $30^{0}$ & $30^{0}$ & 82.068 & -7.551 \\
\hline 12 & $30^{0}$ & $0^{0}$ & $0^{0}$ & 68.056 & -5.767 \\
\hline 13 & $0^{0}$ & $90^{0}$ & $90^{0}$ & 93.061 & -10.347 \\
\hline 14 & $0^{0}$ & $45^{0}$ & $45^{0}$ & 77.104 & -6.656 \\
\hline 15 & $0^{0}$ & $30^{0}$ & $30^{0}$ & 68.114 & -5.523 \\
\hline 16 & $0^{0}$ & $0^{0}$ & $0^{0}$ & 54.947 & -3.591 \\
\hline
\end{tabular}

Table.2: Braking force and negative lift force at different deployment angles



Figure.4: drag and lift generated by the pod 


\section{EPRA International Journal of Research and Development (IJRD)}

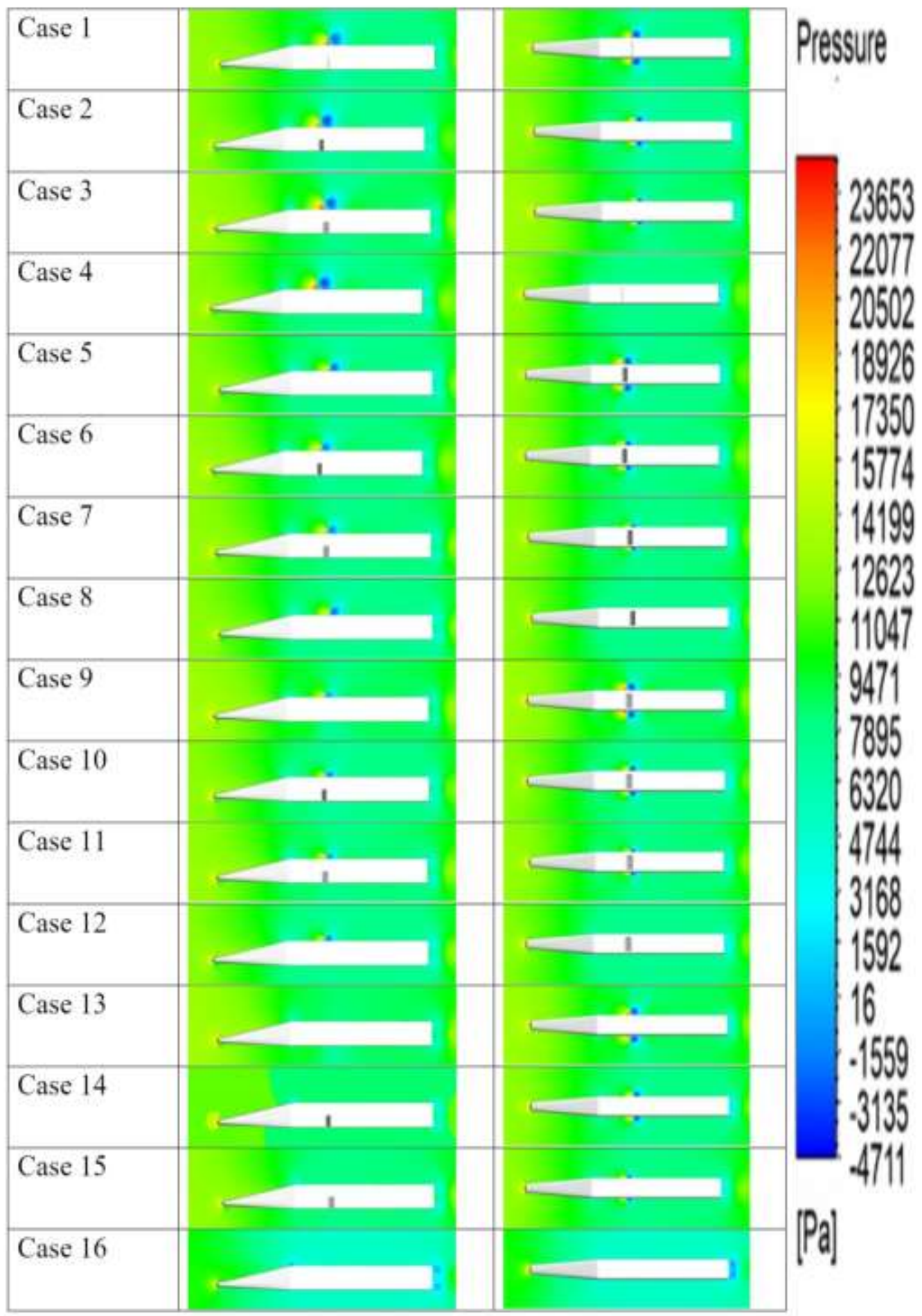

Figure.5: Pressure contours at different Deployment angles 


\section{EPRA International Journal of Research and Development (IJRD)}

Volume: 6 | Issue: 9 | September 2021

- Peer Reviewed Journal

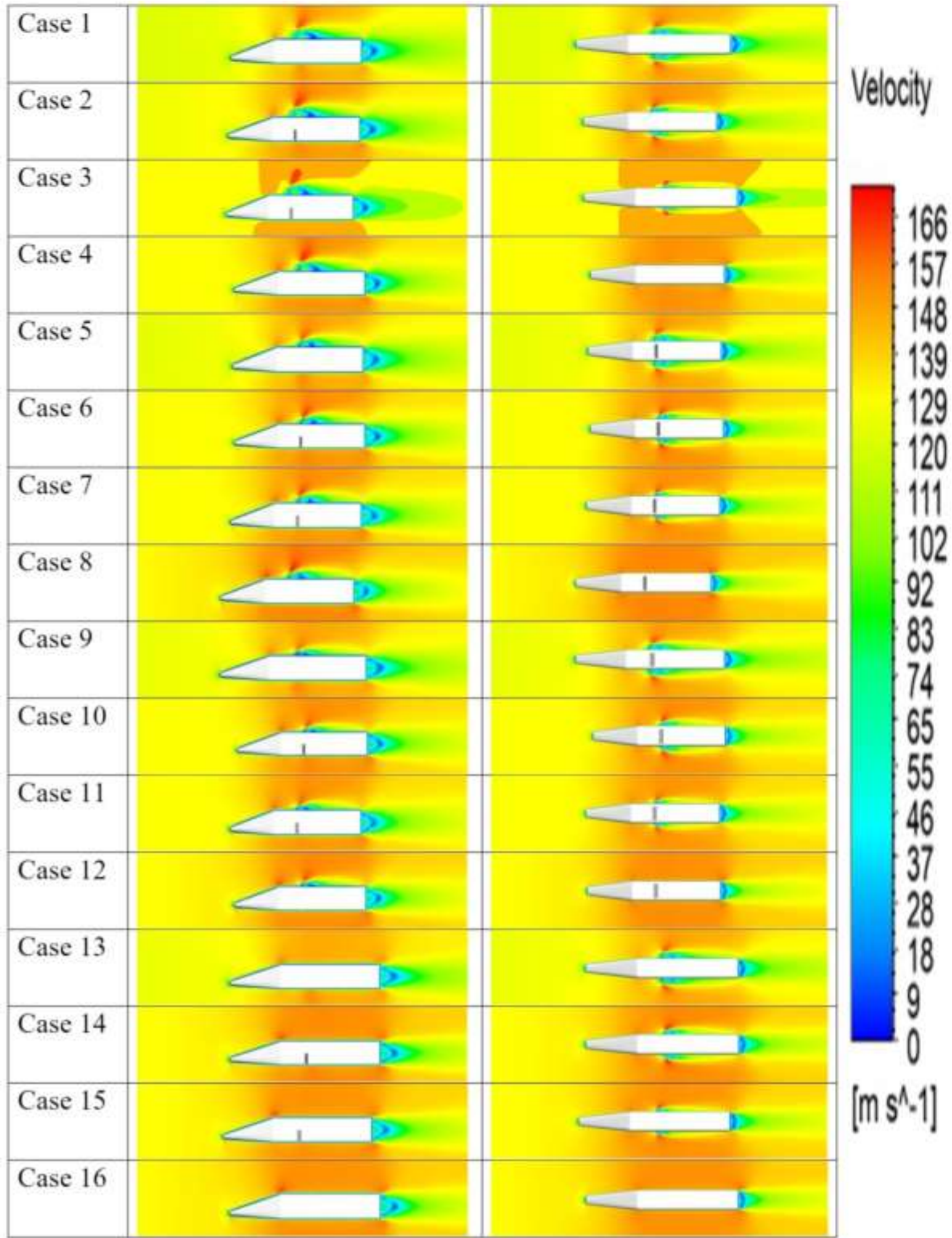

Figure.6: velocity contours at different Deployment angles

(6) 2021 EPRA IJRD | Journal DOI: https://doi.org/10.36713/epra2016 | www.eprajournals.com |85 | 


\section{CONCLUSION AND AREA FOR FURTHER RESEARCH}

Drag force is proportional to the square of velocity, thus increasing the angle of attack of the brake plates against the fluid flow creates a drag force. Sixteen cases of different angle of attack brake plates were considered for analysis as a part of this research work. These all cases were analyzed using Ansys CFX and the simulation result was shown in table 2. Based on the observations from table 2 , it can be concluded that the aerodynamic behaviors (drag and lift) of the pod vary with the variation of the angle of attack of the brake plates. An increase in brake plates increases the drag and deaccelerates the pod. The above results of this research work will contribute towards the development of the aerodynamic braking system of the pods in the future. It is recommended to carry out the analysis of the pod with different shapes of a pod, brake plates, different positions of the brake plate on the pod other than in this research, and by increasing the number of break plates.

\section{REFERENCE}

1. Lim J, Lee C-Y, Lee J-H, You W, Lee K-S, Choi S. Design Model of Null-Flux Coil Electrodynamic Suspension for the Hyperloop. Energies. 2020; 13(19):5075. https://doi.org/10.3390/en13195075
2. Musk, E. 2013. Hyperloop Alpha. SpaceX: Hawthorne, CA, USA.

3. Chen, X., Zhao, L., Ma, J. et al.Aerodynamic simulation of evacuated tube maglev trains with different streamlined designs. J. Mod. Transport. 20, 115-120(2012). https://doi.org/10.1007/BF03325788

4. Puharic, Mirjana \& Matic, Dusan \& Linic, Suzana \& Ristic, Slavica \& Lucanin, Vojkan. (2014). Determination of braking force on the aerodynamic brake by numerical simulations. FME Transaction. 42. 106-111. 10.5937/fmet1402106P.

5. Jianyong, Zuo, Wu Mengling, Tian Chun, Xi Ying, Luo Zhuojun, and Chen Zhongkai. "Aerodynamic Braking Device for High-Speed Trains: Design, Simulation, and Experiment." Proceedings of the Institution of Mechanical Engineers, Part F: Journal of Rail and Rapid Transit 228, no. 3 (March2014):26070. https://doi.org/10.1177/09544 09712471620.

6. H Takami and H Maekawa 2017 J. Phys.: Conf. Ser. 822012061

7. Braun, J., Sousa J., and Pekardan, C. 2017. Aerodynamic Design and Analysis of the Hyperloop. AIAA Journal55 (12): 405360.doi.org/10.2514/1.J055634.

8. Singh, Yadawendra and K. Mehran. "Numerical Analysis for Aerodynamic Behaviour of Hyperloop Pods."(2019). 